\title{
Recurrent Parotid Gland Adenoid Cystic Carcinoma
}

National Cancer Institute

\section{Source}

National Cancer Institute. Recurrent Parotid Gland Adenoid Cystic Carcinoma. NCI

Thesaurus. Code C153804.

The reemergence of parotid gland adenoid cystic carcinoma after a period of remission. 